Aim of the study: To determine the feasibility of sentinel lymph node biopsy (SLNB) for the evaluation of the cervical lymph node status in patients with thyroid tumors.

Material and methods: Twenty-three patients with suspected thyroid cancer were enrolled in the study. $0.5-1.0 \mathrm{ml}$ of $1 \%$ Patent Blue dye was injected intratumorally. After SLNB, thyroidectomy and proper lymphadenectomy were performed.

Results: Sentinel lymph node was detected in $20(86.9 \%)$ patients. Thirty-one SLNs were found -21 (67.7\%) were located in the central neck compartment, $4(12.9 \%)$ in the lateral neck compartment, 6 (19.4\%) in the upper mediastinum. The number of SLNs ranged from 1 to 3 (mean 1.6). Sentinel lymph node was positive in $5(25 \%)$ patients, negative in 15 (75\%) in the final histopathology.

Sentinel lymph nodes were located only in the central neck compartment in $13 \mathrm{pa-}$ tients, and in both the central and lateral neck compartments in 2 patients. In one patient, SLNs were located only in the central neck compartment and upper mediastinum. Three patients had SLNs only in the upper mediastinum, while one had them only in the lateral neck compartment. In one patient a node regarded as SLN was negative, while there were metastases in removed non-sentinel lymph nodes (NSLNs).

In two patients, histopathology of SLNs showed that they were actually parathyroid glands.

Conclusions: Our results confirm that thyroid cancer SLNB is rather easy to carry out. Its performance along with intraoperative examination can help to avoid unnecessary lymphadenectomy. However, it should be kept in mind that parathyroid glands can be stained and removed by mistake during SLNB.

Key words: thyroid cancer, thyroid tumor, sentinel lymph node, sentinel lymph node biopsy, parathyroid glands.

\section{Sentinel lymph node in thyroid tumors - own experience}

\author{
Krzysztof Kaczka, Bartłomiej Luks, Jakub Jasion, Lech Pomorski
}

Department of General and Oncological Surgery, Medical University of Łódź, Poland Maria Sklodowska-Curie Memorial Hospital, Zgierz, Poland

\section{Introduction}

Thyroid carcinoma (TC) has a propensity for cervical lymphatic spread that is usually found in more than one third of patients in the standard review of surgical pathological specimens [1, 2]. However, there is controversy concerning the ideal surgical management of lymph nodes in patients with TC. A number of publications report that cervical metastases did not influence survival for papillary or follicular carcinoma, making selective lymphadenectomy seem a sufficient treatment in thyroid cancer [3-5]. Compared with total thyroidectomy alone, thyroidectomy with lymphadenectomy significantly increases the rate of postoperative complications, especially hypocalcemia [6-8].

Lymph node dissection lengthens operation time. Many metastatic lymph nodes are occult and could be destroyed during postoperative radioiodine therapy [9]. When nodal relapse is observed, it is often possible to remove engaged lymph nodes. On the other hand, two large population-based studies showed increased mortality in patients with regional lymph node metastases $[10,11]$. This is an argument for an operation more extensive than selective lymphadenectomy. Moreover, relapse, which is the worst prognostic factor, is observed most frequently in the lymph nodes $[12,13]$. Nodal metastases can sometimes be treated only surgically if they present no iodine uptake [14]. Perhaps the introduction of sentinel lymph node biopsy (SLNB) could resolve all these controversies. This procedure has brought about a revolution in the management of breast carcinoma and melanoma. The sentinel node status (presence or absence of metastasis) is, almost always, compatible with the status of regional lymph nodes. Therefore, intraoperative evaluation of sentinel node(s) could help to define the extent of lymphadenectomy. In the case of a negative SLNB, there is no need to perform lymphadenectomy and patients can avoid complications related to it. The limited dissection could decrease the risk of complications, especially hypoparathyroidism. In addition, SLNB can help to identify occult metastases outside the central compartment. This procedure is a logical alternative to extended elective lymphadenectomy.

The objective of this study was to determine the feasibility of SLNB for the evaluation of the cervical lymph node status in patients with thyroid carcinoma.

\section{Material and methods}

Twenty-three patients (18 women and 5 men) underwent SLNB in the Department of General Surgery and Oncology of the Medical University of Lodz from December 2009 to April 2011. They were suspected of or diagnosed with thyroid carcinoma based on fine needle aspiration biopsy (FNAB). Only patients primarily operated on were enrolled in the study. Patients after partial thyroidectomy and lymphadenectomy, operated on due to local recurrence, were excluded from the series. The operation was performed under general anesthesia. The whole thyroid gland was exposed during the operation. Tissues were prepared carefully in order not to disrupt the flow of the lymph. Subsequently, $0.5-1.0 \mathrm{ml}$ of 1\% Patent Blue dye (Guerbet GmbH Germany) was injected intratumorally, very slowly, under 
low pressure, using a 27-G needle and insulin syringe. Care was taken not to accidentally stain the surrounding structures. The volume of blue dye depended on the diameter of the tumor. $0.5 \mathrm{ml}$ was injected if the diameter was $2 \mathrm{~cm}$ or below. $1 \mathrm{ml}$ of blue dye was used for tumors larger than $2 \mathrm{~cm}$. Blue stained lymph nodes were considered sentinel lymph nodes (SLNs). They were removed and sent for final histopathological examination as well as molecular examinations. Frozen section examinations were not performed. After SLNB, thyroidectomy and proper lymphadenectomy (bilateral central and lateral lymphadenectomy on the side of the tumor were performed) were performed. Other removed lymph nodes were defined as non-sentinel lymph nodes (NSLNs). In our study, the results of SLNB did not change the extent of lymphadenectomy. The location of lymph nodes was determined based on the Dralle et al. classification [15]. The protocol study was approved by the Ethics Committee of the Medical University of Lodz, Poland.

Statistica 10.0 software was used for analysis (StatSoft, Tulsa, OK, USA).
Table 1. Positive predictive value, negative predictive value, sensitivity and specificity for SLNB

\begin{tabular}{llc}
\hline Positive predictive value & 1.0000 & Cl: $0.5655-1$ \\
\hline Negative predictive value & 0.4667 & Cl: $0.2481-0.6988$ \\
\hline Sensitivity & 0.3846 & Cl: $0.1771-0.6448$ \\
\hline Specificity & 1.0000 & Cl: $0.6457-1$
\end{tabular}

\section{Statistical analysis}

Positive predictive value, negative predictive value, sensitivity and specificity for SLNB were calculated (Table 1).

\section{Results}

\section{Final results of the histological examination} of tumors

Final histopathological examination revealed 15 malignant and 8 benign tumors. Papillary thyroid carcinoma (PTC) was diagnosed in 13 patients, medullary thyroid carcinoma (MTC) in two patients, and adenoma in 8 patients (Table 2).

Table 2. Final results of the histopathological examination

\begin{tabular}{|c|c|c|c|c|c|c|}
\hline Patient No. & $\begin{array}{l}\text { Patient } \\
\text { initials }\end{array}$ & Age & Gender & Histopathology & Tumor location & Size $(\mathrm{mm})$ \\
\hline 1 & P.B. & 41 & female & classical variant of papillary carcinoma & right lobe & 30 \\
\hline 2 & B.M. & 41 & female & classical variant of papillary carcinoma & left lobe & 20 \\
\hline 3 & E.R. & 50 & female & classical variant of papillary carcinoma & right lobe & 7 \\
\hline 4 & K.W. & 49 & male & classical variant of papillary carcinoma & right lobe & 9 \\
\hline 5 & W.K. & 65 & male & classical variant of papillary carcinoma & $\begin{array}{l}\text { upper pole of the right lobe } \\
\text { (two foci) }\end{array}$ & 2 and 7 \\
\hline 6 & A.M. & 68 & female & classical variant of papillary carcinoma & left lobe & 20 \\
\hline 7 & P.P. & 47 & male & classical variant of papillary carcinoma & upper pole of the right lobe & 18 \\
\hline 8 & M.N. & 37 & female & classical variant of papillary carcinoma & upper pole of the left lobe & 25 \\
\hline 9 & W.R. & 73 & female & classical variant of papillary carcinoma & left lobe & 20 \\
\hline 10 & D.B. & 47 & male & medullary carcinoma & left lobe & 30 \\
\hline 11 & K.K. & 34 & female & follicular variant of papillary thyroid carcinoma & upper pole of the right lobe & 20 \\
\hline 12 & J.K. & 65 & male & medullary carcinoma & left lobe & 9 \\
\hline 13 & M.K. & 65 & female & classical variant of papillary carcinoma & right lobe & 25 \\
\hline 14 & J.D. & 71 & female & classical variant of papillary carcinoma & right lobe & 20 \\
\hline 15 & M.J. & 44 & female & follicular variant of papillary thyroid carcinoma & $\begin{array}{l}\text { border of the isthmus } \\
\text { and right lobe }\end{array}$ & 6 \\
\hline 16 & H.N. & 55 & female & adenoma & isthmus & 15 \\
\hline 17 & T.C. & 53 & female & adenoma & right lobe & 18 \\
\hline 18 & K.M. & 54 & female & adenoma & right lobe & 30 \\
\hline 19 & M.B. & 31 & female & adenoma & $\begin{array}{l}\text { border of the isthmus } \\
\text { and right lobe }\end{array}$ & 13 \\
\hline 20 & B.H. & 31 & female & adenoma & upper pole of the right lobe & 8 \\
\hline 21 & K.Z. & 67 & female & adenoma & lower pole of the left lobe & 35 \\
\hline 22 & S.P. & 75 & female & adenoma & lower pole of the left lobe & 10 \\
\hline 23 & D.T. & 37 & female & adenoma & left lobe & 20 \\
\hline
\end{tabular}


Five, 6,3 and 1 patients were classified with pT1a, pT1b, pT2 and pT3, respectively according to the $7^{\text {th }}$ WHO Classification.

The classic type of papillary thyroid carcinoma was diagnosed in 11 patients. Two patients were considered to have the follicular variant of PTC. The mean tumor size was $1.74 \mathrm{~cm}$ (range: $0.2-3.5 \mathrm{~cm}$ ) (Table 2). Sixteen tumors were larger than $1 \mathrm{~cm}, 8$ were equal to or smaller than $1 \mathrm{~cm}$ (Table 2). One patient, W.K., had 2 foci of papillary carcinoma (Table 2). Thyroid capsule infiltration was detected in 6 out of 15 (37.5\%) patients with malignant neoplasms.

\section{Results of sentinel lymph node biopsy}

Sentinel lymph nodes were detected, by using Patent Blue dye, in 20 out of 23 patients (86.9\%) (Table 3). Among them, eleven had PTC, two MTC, and 7 benign lesions. Thirty-one SLNs were found - 21 (67.7\%) were located in the central neck compartment (la and lb), 4 (12.9\%) in the lateral neck compartment, 6 (19.4\%) in the upper mediastinum (Table 3). The number of SLNs ranged from 1 to 3 (mean 1.6) (Table 3). Sentinel lymph node was positive in $5(25 \%)$ patients (P.B., A.M., M.N., D.B., K.K.), and nega- tive in 15 (75\%) patients in the final histopathological examination (Table 3).

Four patients with PTC had positive SLN, while the remaining seven had negative SLN. One of the two patients with medullary thyroid carcinoma (MTC) had SLN involved.

Sentinel lymph nodes were located only in the central neck compartment in 13 patients, and in both the central and lateral neck compartments in 2 patients. In one patient, SLNs were located only in the central neck compartment and upper mediastinum. Three patients had SLNs only in the upper mediastinum, while one patient had them only in the lateral neck compartment (Table 3). In one patient (J.K.), a node regarded as SLN was negative, while in removed NSLNs metastases were found in the final histopathological examination. In two patients, histopathology of SLNs showed that they were actually parathyroid glands. None of the patients presented permanent or temporary hypocalcemia after the operation. There was no allergy to Patent Blue dye in any patient.

\section{Discussion}

The standard treatment of thyroid carcinoma generally includes total thyroidectomy together with regional lymph

Table 3. Location of lymph nodes in the compartments

\begin{tabular}{|c|c|c|c|c|c|c|c|c|c|c|c|}
\hline \multirow[t]{2}{*}{ Patient No. } & \multirow{2}{*}{$\begin{array}{l}\text { Patient } \\
\text { initials }\end{array}$} & \multicolumn{10}{|c|}{ No. of metastatic/all lymph nodes in compartments } \\
\hline & & $\begin{array}{l}\text { SLNs } \\
\text { in la }\end{array}$ & $\begin{array}{l}\text { All LNs } \\
\text { in la }\end{array}$ & $\begin{array}{l}\text { SLNs } \\
\text { in Ib }\end{array}$ & $\begin{array}{l}\text { All LNs } \\
\text { in lb }\end{array}$ & $\begin{array}{l}\text { SLNs } \\
\text { in II }\end{array}$ & $\begin{array}{l}\text { All LNs } \\
\text { in II }\end{array}$ & $\begin{array}{l}\text { SLNs } \\
\text { in III }\end{array}$ & $\begin{array}{l}\text { All LNs } \\
\text { in III }\end{array}$ & $\begin{array}{l}\text { SLNs } \\
\text { in IV }\end{array}$ & $\begin{array}{c}\text { All LNs } \\
\text { in IV }\end{array}$ \\
\hline 1 & P.B. & $2 / 2$ & $2 / 2$ & 0 & 0 & 0 & $0 / 2$ & 0 & $0 / 2$ & 0 & $0 / 3$ \\
\hline 2 & B.M. & 0 & $0 / 5$ & $0 / 1$ & $0 / 1$ & 0 & $0 / 9$ & 0 & $0 / 13$ & 0 & $0 / 9$ \\
\hline 3 & E.R. & 0 & 0 & $0 / 1$ & $0 / 4$ & 0 & 0 & 0 & 0 & 0 & 0 \\
\hline 4 & K.W. & 0 & $0 / 1$ & 0 & 0 & $0 / 3$ & $0 / 13$ & 0 & 0 & 0 & $0 / 8$ \\
\hline 5 & W.K. & 0/1 & $0 / 3$ & 0 & 0 & 0 & 0 & 0 & 0 & 0 & 0 \\
\hline 6 & A.M. & 0 & 0 & $1 / 1$ & 1 & 0 & 0 & 0 & $3 / 11$ & 0 & 0 \\
\hline 7 & P.P. & $0 / 2$ & $0 / 3$ & 0 & 0 & 0 & $0 / 16$ & 0 & 0 & 0 & 5 \\
\hline 8 & M.N. & 0 & 0 & $2 / 2$ & $2 / 4$ & 0 & 0 & $1 / 1$ & $1 / 1$ & 0 & 0 \\
\hline 9 & W.R. & 0 & 0 & $0 / 1$ & $0 / 3$ & 0 & 0 & $0 / 1$ & $0 / 12$ & 0 & 0 \\
\hline 10 & D.B. & 0 & 0 & $2 / 2$ & $2 / 3$ & 0 & 0 & 0 & $0 / 2$ & 0 & $0 / 1$ \\
\hline 11 & K.K. & $1 / 1$ & $1 / 1$ & 0 & 0 & 0 & 0/1 & 0 & 0 & 0 & 0 \\
\hline 12 & J.K. & 0 & 0 & $0 / 1$ & $1 / 3$ & 0 & 0 & 0 & $3 / 10$ & 0 & 0 \\
\hline 13 & M.K. & 0 & $0 / 2$ & 0 & 0 & 0 & $0 / 3$ & 0 & $0 / 12$ & 0 & 0 \\
\hline 14 & J.D. & 0 & $0 / 4$ & 0 & 0 & 0 & 0 & 0 & 0 & 0 & 0 \\
\hline 15 & M.J. & 0 & 0 & $0 / 1$ & $0 / 8$ & 0 & 0 & 0 & $0 / 16$ & $0 / 2$ & $0 / 8$ \\
\hline 16 & H.N. & 0 & 0 & $0 / 1$ & $0 / 2$ & 0 & 0 & 0 & 0 & 0 & 0 \\
\hline 17 & T.C. & 0 & 0 & 0 & 0 & 0 & 0 & 0 & 0 & $0 / 1$ & $0 / 1$ \\
\hline 18 & K.M. & $0 / 1$ & $0 / 1$ & 0 & 0 & 0 & 0 & 0 & 0 & 0 & 0 \\
\hline 19 & M.B. & 0 & 0 & 0 & 0 & 0 & 0 & 0 & 0 & $0 / 2$ & $0 / 2$ \\
\hline 20 & B.H. & 0/1 & 0/1 & 0 & 0 & 0 & 0 & 0 & 0 & 0 & 0 \\
\hline 21 & K.Z. & 0 & 0 & $0 / 1$ & $0 / 1$ & 0 & 0 & 0 & 0 & 0/1 & $0 / 3$ \\
\hline 22 & S.P. & $0 / 1$ & $0 / 1$ & 0 & 0 & 0 & 0 & 0 & 0 & 0 & 0 \\
\hline 23 & D.T. & 0 & $0 / 2$ & 0 & 0 & 0 & 0 & 0 & 0 & 0 & 0 \\
\hline
\end{tabular}

SLNs - sentinel lymph nodes, LN - lymph nodes 
node dissection, ${ }^{131}$ I treatment, and life-long TSH-suppressive thyroid hormone replacement. However, the extent of lymph node resection remains a matter of controversy. According to some authors, selective lymphadenectomy seems a sufficient treatment in thyroid carcinoma [3-5]. Additionally, elective lymphadenectomy increases the rate of postoperative complications, especially hypocalcemia [6-8]. Lymph node dissection is also a time-consuming procedure. On the other hand, some studies present a negative prognostic impact of lymph node metastases, especially in patients older than 45 years $[12,16]$. This is an argument for an operation more extensive than selective lymphadenectomy. In addition, recurrence, which is the worst prognostic factor, appears most frequently in lymph nodes in patients older than 45 years [12, 17]. Nodal metastases often present no iodine uptake and can only be treated surgically $[17,18]$. Cady and Rossi created an AMES scoring system (age, metastasis, extent, size of tumor) assigning patients to groups of low and high risk. The high-risk group includes: men with PTC above 45 years of age, women above 50 years of age, distant metastasis, extracapsular invasion and tumor size larger than $5 \mathrm{~cm}$ [17, 19]. Nodal disease in older patients in the high-risk group with PTC is associated with a 78\% mortality rate [19]. In any case, as only patients with lymph node metastases would benefit from lymph node treatment, it would be important to know the status of the lymph nodes before making a therapeutic strategy choice.

As a way to resolve these controversies, the application of sentinel lymph node biopsy has generated interest. Because of its high sensitivity, accuracy and low false-negative rate in predicting the regional lymph node status, SLNB has obtained widespread consensus and replaced routine lymphadenectomy as the standard for staging in breast cancer and melanoma. The success of SLNB in breast cancer and melanoma has set a good example for other types of solid tumors: colorectal cancer, gastric cancer, esophageal cancer, head and neck tumors, lung cancer and gynecological malignancies [20-33]. Perhaps in the case of thyroid carcinoma it will be a standard procedure. Kelemen et al., who used blue dye, were the first to be able to note the feasibility of the SLNB procedure in thyroid surgery [34]. In their preliminary study, the authors identified SLNs in all 12 patients with thyroid cancer; 5 SLNs were positive for metastases. In 1999 Gallowitsch et al. and in 2001 Sahin et al. used radioisotopes for the same purpose. Both reported favorable results for detecting SLNS by this technique $[35,36]$. A few meta-analyses have evaluated the usefulness of SLNB in thyroid surgery [37, 38]. Many authors have investigated the feasibility and potential utility of SLN biopsy in thyroid neoplasms, both malignant and benign, reporting encouraging results, albeit based on limited case series and without following commonly accepted rules. In our study we were able to find SLNs in $83.3 \%$ of patients. This result is similar to the other studies [37, 38]. To the best of our knowledge, the detection rate is above $60 \%$ in all published studies but one [39]. The authors, who applied the radioisotope method, achieved even better results [4043]. In three of the studies surgeons managed to find SLNs in all patients [40, 41, 43]. In the fourth study the detection rate was also excellent $-96.9 \%$ [42]. The results of those stud- ies proved that SLNB employing radiotracer technique is feasible to perform. However, this procedure is not available in many centers. It requires special equipment and is time-consuming. Although it has been proved that using a radiocolloid is safe in SLNB for breast cancer and melanoma, some of the medical staff have concerns about safety. Doses of the radiocolloid used for SLNB for thyroid carcinoma are not higher so there is no reason not to believe that the procedure is safe $[44,45]$. There are 2 studies concerning thyroid carcinoma where radioisotope and blue dye were used together. Catarci's group found SLNs in all 6 patients [46]. In another study, on a larger group of patients $(n=43)$, detection rates for both methods were almost the same -93\% for the blue dye and $88.4 \%$ for the radioisotope technique [47]. Our study shows that the SLNB technique is feasible, repeatable and accurate, detecting the SLN in $83.3 \%$ of patients. This sensitivity is similar to that reported by a majority of the other studies [37, 38]. We do not know why we were not able to detect SLNs in all patients. Perhaps we disrupted the lymph flow during dye injection or made another technical error. The results of SLNBS in our study have not changed the extent of operations because SLNB for thyroid cancer is not a standardized procedure. Thirty-two SLNs were found in our patients. The number of SLNs ranged from 1 to 3 (mean 1.6). Sentinel lymph nodes were engaged in 5 patients (25\%), and negative in 15 patients (75\%). Four PTC patients had positive SLN; the remaining seven PTC patients had negative SLN. One of the two patients with medullary thyroid carcinoma (MTC) had the SLN involved. The percentage of involved SLNs is close to that in other studies [48-50].

Sentinel lymph nodes in a majority of our patients (13) were found only in the central neck compartment. However, SLNs were observed outside the central neck compartment in 4 patients. Three patients had SLNs only in the upper mediastinum, while one patient had them only in the lateral neck compartment. Lymphadenectomy outside the central neck compartment is not routinely performed in many centers. Perhaps SLNB could help to identify cases that require it to be performed. Three patients had SLNs in two compartments -2 in the central and lateral compartments and 1 in the central and upper mediastinum compartments.

Regrettably, in one patient a node regarded as SLN was negative, while metastases were found in removed NSLNs in the final histopathological examination. It is a disadvantage of the method. That may be due to the fact that we have been performing SLNB for a short time so we are not experienced in this technique. However, it is also possible to observe the alternative lymph flow from the thyroid. It may lead to the occurrence of skip metastases (a positive lymph node in the lateral compartment without positive lymph nodes in the central compartment) [51]. We believe that that phenomenon should be evaluated on a greater number of patients before introducing SLNB as a standard procedure.

In 3 patients, histopathology of SLNs showed that they were actually parathyroid glands. Fortunately, these patients had no permanent or temporary hypocalcemia after the operation. This complication is typical of thyroid SLNB and is regrettably the most serious complication. It was earlier reported by Rubello et al. and Abdalla et al. [52, 53]. 
We suppose that, in order to avoid it, the parathyroid gland should be located before blue dye injection. There is a need to look for a dye other than Patent Blue or radiotracer with lower affinity to parathyroid glands. Perhaps the introduction of nanoparticles or indocyanine green will solve this problem $[54,55]$.

Our results confirm that thyroid cancer SLNB is rather easy to carry out, but it should be kept in mind that parathyroid glands can be stained and removed by mistake. Its performance along with intraoperative examination can help to avoid unnecessary lymphadenectomy in the central and lateral compartments. However, central neck dissection has been proven to improve staging of the neck, use of adjuvant radioiodine treatment and ten-year disease-specific survival, in comparison to patients without central neck dissection [56]. From this perspective, SLNB can be considered a promising tool, but it needs to be tested in large prospective studies before any evidence-based conclusions can be reached.

The study received financial support from the Ministry of Science and Higher Education in Poland - grant number N N403 220537.

\section{References}

1. Hunt JP, Buchmann LO, Wang L, Abraham D. An analysis of factors predicting lateral cervical nodal metastases in papillary carcinoma of the thyroid. Arch Otolaryngol Head Neck Surg 2011; 137: 1141-5.

2. Smith VA, Sessions RB, Lentsch EJ. Cervical lymph node metastasis and papillary thyroid carcinoma: does the compartment involved affect survival? Experience from the SEER database. J Surg Oncol 2012; 106: 357-62.

3. Steinmüller T, Klupp J, Rayes N, Ulrich F, Jonas S, Gräf KJ, Neuhaus P. Prognostic factors in patients with differentiated thyroid carcinoma. Eur J Surg 2000; 166: 29-33.

4. Ward LS, Souza SL, Assumpção LV. The impact of nodal metastases on prognosis of well-differentiated thyroid cancer suggests the prac tice of prophylactic neck dissection. Arch Otolaryngol Head Neck Surg 2003; 129: 495-6.

5. Bhattacharyya N. A population-based analysis of survival factors in differentiated and medullary thyroid carcinoma. Otolaryngol Head Neck Surg 2003; 128: 115-23.

6. Roh JL, Park JY, Park Cl. Prevention of postoperative hypocalcemia with routine oral calcium and vitamin D supplements in patients with differentiated papillary thyroid carcinoma undergoing total thyroidectomy plus central neck dissection. Cancer 2009; 115: 251-8.

7. Bergenfelz A, Jansson S, Kristoffersson A, Mårtensson H, Reihnér E, Wallin G, Lausen I. Complications to thyroid surgery: results as reported in a database from a multicenter audit comprising 3660 patients. Langenbecks Arch Surg 2008; 393: 667-73.

8. Shen WT, Ogawa L, Ruan D, Suh I, Duh QY, Clark OH. Central neck lymph node dissection for papillary thyroid cancer: the reliability of surgeon judgement in predicting which patients will benefit. Surgery 2010; 148: 398-403.

9. Prpić M, Jukić T, Murgić J, Borić M, Stanicić J, Kusić Z. Postoperative use of radioiodine (131-I): review of recommendations and guidelines. Coll Antropol 2011; 35: 587-94.

10. Lundgren $\mathrm{Cl}$, Hall P, Dickman PW, et al. Clinically significant prognostic factors for differentiated thyroid carcinoma: a population-based, nested case-control study. Cancer 2006; 106: 524-31.

11. Podnos YD, Smith D, Wagman LD, et al. The implication of lymph node metastasis on survival in patients with well-differentiated thyroid cancer. Am Surg 2005; 71: 731-4.

12. Beasley NJ, Lee J, Eskil S, Walfish P, Witterick JL, Freeman JL. Impact of nodal metastases on prognosis in patients with well-differenti- ated thyroid cancer. Arch Otolaryngol Head Neck Surg 2002; 128: 825-8.

13. Witte J, Goretzki PE, Dicken J, Simon D, Roher HD. Importance of lymph node metastases in follicular thyroid cancer. World I Surg 2002; 26: 1017-22.

14. Creach KM, Gillanders WE, Siegel BA, Haughey BH, Moley JF, Grigsby PW. Management of cervical nodal metastasis detected on I-131 scintigraphy after initial surgery of well-differentiated thyroid carcinoma. Surgery 2010; 148: 1198-204.

15. Dralle H, Gimm O. Lymphadenektomie beim Schilddrüsencarcinom. Chirurg 1996; 67: 788-806.

16. Zaydfudim V, Feurer ID, Griffin MR, Phay JE. The impact of lymph node involvement on survival in patients with papillary and follicular thyroid carcinoma. Surgery 2008; 144: 1070-7.

17. Cady B, Rossi R. An expanded view of risk-group definition in differentiated thyroid carcinoma. Surgery 1998; 104: 947-53.

18. Jarzab B. Treatment of thyroid cancer (in Polish). Pol J Endocrinol 1995; 46: $25-35$.

19. Cady B. Our AMES is true: how an old concept still hits the mark; or, risk group assignment points the arrow to rational therapy selection in differentiated thyroid cancer. Am J Surg 1997; 174: 462-468.

20. Stojadinovic A, Allen PJ, Protic M, Potter JF, Shriver CD, Nelson JM, Peoples GE. Colon sentinel lymph node mapping: practical surgical applications. J Am Coll Surg 2005; 201: 297-313.

21. Bertagnolli M, Miedema B, Redston M, et al. Sentinel node staging of resectable colon cancer: results of a multicenter study. Ann Surg 2004; 240: 624-30.

22. Roukos DH. Current status and future perspectives in gastric cancer management. Cancer Treat Rev 2000; 26: 243-5.

23. Kitagawa Y, Fujii H, Kumai K, et al. Recent advances in sentinel node navigation for gastric cancer: a paradigm shift of surgical management. J Surg Oncol 2005; 90: 147-52.

24. Kitagawa Y, Fujii H, Mukai M, et al. The role of the sentinel lymph node in gastrointestinal cancer. Surg Clin North Am 2000; 80: 799809.

25. Yasuda S, Shimada H, Chino Q, et al. Sentinel lymph node detection with Tc-99m tin colloids in patients with esophagogastric cancer (in Japanese). J Clin Oncol 2003; 33: 68-72.

26. Lamb PJ, Griffin SM, Burt AD, Lloyd J, Karat D, Hayes N. Sentinel node biopsy to evaluate the metastatic dissemination of oesophageal adenocarcinoma. Br J Surg 2005; 92: 60-7.

27. Ross GL, Soutar DS, MacDonald DG, et al. Sentinel node biopsy in head and neck cancer: preliminary results of a multicenter trial. Ann Surg Oncol 2004; 11: 690-6.

28. Ross GL, Soutar DS, MacDonald DG, Shoaib T, Camilleri IG, Robertson AG. Improved staging of cervical metastases in clinically nodenegative patients with head and neck squamous cell carcinoma. Ann Surg Oncol 2004; 11: 213-8.

29. Ross G, Shoaib T, Soutar DS, Camilleri IG, Gray HW, Bessent RG, Robertson AG, MacDonald DG. The use of sentinel node biopsy to upstage the clinically NO neck in head and neck cancer. Arch Otolaryngol Head Neck Surg 2002; 128: 1287-91.

30. Little AG, Dehoyos A, Kirgan DM, Arcomano TR, Murray KD. Intraoperative lymphatic mapping for non-small cell lung cancer: the sentinel node technique. J Thorac Cardiovasc Surg 1999; 117: 220-4.

31. Lardinois D, Brack T, Gaspert A, Spahr T, Schneiter D, Steinert HC, Weder W. Bronchoscopic radioisotope injection for sentinel lymph-node mapping in potentially resectable non-small-cell lung cancer. Eur J Cardiothorac Surg 2003; 23: 824-7.

32. Liptay MJ, Masters GA, Winchester DJ, Edelman BL, Garrido BJ. Intraoperative radioisotope sentinel lymph node mapping in non-small cell lung cancer. Ann Thorac Surg 2000; 70: 384-9.

33. Paplicki A, Dańska-Bidzińska A, Sobiszewski P, Bidziński M. The role of the sentinel lymph node (SLN) in gynaecological malignancies is it time to change the management methods? Prz Menopauz 2011; 15: 368-71.

34. Kelemen PR, Van Herle AJ, Giuliano AE. Sentinel lymphadenectomy in thyroid malignant neoplasms. Arch Surg 1998; 133: 288-92.

35. Gallowitsch HJ, Mikosch P, Kresnik E, Starlinger M, Lind P. Lymphoscintigraphy and gamma probe-guided surgery in papillary thyroid carcinoma: the sentinel lymph node concept in thyroid carcinoma. Clin Nucl Med 1999: 24: 744-6. 
36. Sahin M, Yapici O, Dervisoglu A, Basoglu T, Canbaz F, Albayrak S, Citak A. Evaluation of lymphatic drainage of cold thyroid nodules with intratumoral injection of Tc-99m nanocolloid. Clin Nucl Med 2001; 26: 602-5.

37. Raijmakers PGHM, Paul MA, Lips P. Sentinel node detection in patients with thyroid carcinoma: a meta-analysis. World J Surg 2008; 32: 1961-67.

38. Balasubramanian SP, Harrison BJ. Systematic review and meta-analysis of sentinel node biopsy in thyroid cancer. Br J Surg 2011; 98: 334-44.

39. Pelizzo MR, Boschin IM, Toniato A, Bernante P, Piotto A, Rinaldo A, Ferlito $A$. The sentinel node procedure with Patent Blue $V$ dye in the surgical treatment of papillary thyroid carcinoma. Acta Otolaryngol 2001; 121: 421-4.

40. Stoeckli SJ, Pfaltz M, Steinert H, Schmid S. Sentinel lymph node biopsy in thyroid tumors: a pilot study. Eur Arch Otorhinolaryngol 2003; 260: 364-8.

41. Pelizzo MR, Rubello D, Boschin IM, et al. Contribustion of SLN investigation with $99 \mathrm{mTc}$-nanocolloid in clinical staging of thyroid cancer: technical feasibility. Eur J Nucl Mol Imaging 2007; 34: 934-8.

42. Carcoforo P, Feggi L, Trasforini G, et al. Use of preoperative lymphoscintigraphy and intraoperative gamma-probe detection for iden tification of the sentinel lymph node in patients with papillary thyroid carcinoma. EJSO 2007; 33: 1075-80.

43. Boschin IM, Toniato A, Piotto A, Ide EC, Casara D, Guolo A, Rubello D, Pelizzo M. 99Tc Nanocolloid sentinel node procedure in thyroid carcinoma. Langenbecks Arch Surg 2008; 393: 705-8.

44. Nejc D, Wrzesień M, Piekarski J, Olszewski J, Pluta P, Kuśmierek J, Jeziorski A. Sentinel node biopsy in skin melanoma patients - measurements of absorbed doses of radiation to the hands of medical staff. J Surg Oncol 2006; 93: 355-61.

45. Nejc D, Wrzesień M, Piekarski J, Olszewski J, Pluta P, Kuśmierek J, Jeziorski A. Sentinel node biopsy in patients with breast cancer - evaluation of exposure to radiation of medical staff. Eur J Surg Oncol 2006; 32: $133-8$

46. Catarci M, Zaraca F, Angeloni R, Mancini B, de Filippo MG, Massa R, Carboni M, Pasquini G. Preoperative lymphoscintigraphy and sentinel lymph node biopsy in papillary thyroid cancer. A pilot study. J Surg Oncol 2001; 77: 21-4.

47. Lee SK, Choi JH, Lim HI, Kim WW, Kim SM. Sentinel lymph node biopsy in papillary thyroid cancer. Comparison study of blue dye method and combined radioisotope and blue dye method in papillary thyroid cancer. Eur J Surg Oncol 2009; 35: 974-9.

48. Ji YB, Lee KJ, Park YS, Hong SM, Paik SS, Tae K. Clinical efficacy of sentinel lymph node biopsy using methylene blue dye in clinically node-negative papillary thyroid carcinoma. Ann Surg Oncol 2012; 19: 1868-73.

49. Cunningham DK, Yao KA, Turner RR, Singer FR, Van Herle AR, Giuliano AE. Sentinel lymph node biopsy for papillary thyroid cancer: 12 years of experience at a single institution. Ann Surg Oncol 2010; 17: 2970-5.

50. Anand SM, Gologan O, Rochon L, Tamilia M, et al. The role of sentinel lymph node biopsy in differentiated thyroid carcinoma. Arch Otolaryngol Head Neck Surg 2009; 135: 1199-204.

51. Machens A, Holzhausen HJ, Dralle H. Skip metastases in thyroid leaping the central lymph node compartment. Arch Surg 2004; 139 43-5.

52. Rubello D, Nanni C, Merante Boschin I, et al. Sentinel lymph node (SLN) procedure with patent $V$ blue dye in 153 patients with papillary thyroid carcinoma (PTC): is it an accurate staging method? J Exp Clin Cancer Res 2006; 25: 483-6.

53. Abdalla HM. Feasibility of sentinel lymph node detection in nodular thyroid disease. J Egypt Natl Canc Inst 2006; 18: 35-40.

54. Hao RT, Chen J, Zhao LH, Liu C, Wang OC, Huang GL, Zhang XH, Zhao J. Sentinel lymph node biopsy using carbon nanoparticles for Chinese patients with papillary thyroid microcarcinoma. Eur J Surg Oncol 2012: 38: 718-24.
55. Aoyama K, Kamio T, Ohchi T, Nishizawa M, Kameoka S. Sentinel lymph node biopsy for breast cancer patients using fluorescence navigation with indocyanine green. World J Surg Oncol 2011; 9: 157.

56. Barczyński M, Konturek A, Stopa M, Nowak M. Prophylactic central neck dissection for papillary thyroid cancer. Br J Surg 2013; 100: 410-8.

\section{Address for correspondence}

\section{Krzysztof Kaczka}

Department of General and Oncological Surgery

Medical University of Łódź

Maria Sklodowska-Curie Memorial Hospital

Parzęczewska 35

95-100 Zgierz, Poland

tel. +48503068 786

e-mail: krzysztofkaczka@poczta.fm

Submitted: 6.07.2012

Accepted: $\quad 5.02 .2013$ 